\title{
SEROTONIN AUTORECEPTORS ON DORSAL RAPHE NEURONS: STRUCTURE-ACTIVITY RELATIONSHIPS OF TRYPTAMINE ANALOGS $^{1}$
}

\author{
MICHAEL A. ROGAWSKI ${ }^{2}$ AND GEORGE K. AGIIAJANIAN
}

Departments of Pharmacology and Psychintry, Yale Iniversity School of Medicine and the Connecticut Mental Health Center, New Haven, Connecticut 06510

\begin{abstract}
A series of indole-ethylamines were tested for their ability to suppress the spontaneous firing of single dorsal raphe serotonergic neurons in the rat. The compounds were all derivatives of either tryptamine or $N, N$-dimethyltryptamine possessing hydroxy or methoxy substituents on the benzene ring portion of the indole nucleus. Their activity was assessed using quantitative microiontophoresis or following systemic (intravenous) administration. The serotonin autoreceptor or so-called " $\mathrm{S}_{2}$ receptor" mediating the inhibition of raphe serotonergic neurons was found to exhibit a high degree of structural specificity among the closely related tryptamine analogs. The following structureactivity rules were demonstrated: (1) for either hydroxy or methoxy derivatives, the relative favorability of the ring positions conforms to the series $5 \gg 4>6$; (2) methoxy derivatives are more sensitive to a shift of the ring substituent from the 5- to the 4-or 6-positions than are hydroxy compounds; and (3) activity is enhanced by $N, N$-dimethylation. Furthermore, addition of a methyl group at the 7-position of 5-methoxy- $N, N$-dimethyltryptamine markedly reduces the activity of this potent agonist. Of the radioligands which label brain serotonin receptors, the pharmacological characteristics of $\mathrm{D}-\left[{ }^{3} \mathrm{H}\right]$ lysergic acid diethylamide binding best correspond to those displayed by the $S_{2}$ receptor as determined in the present physiological analysis, although sufficient data are not yet available to make a complete comparison.
\end{abstract}

The spontaneous firing of serotonin (5-H'T)-containing neurons in the dorsal raphe nucleus is suppressed by certain indolealkylamines containing the tryptamine nucleus. Inhibitory effects occur following the systemic administration of indole-derived serotonergic agonists which gain access to the brain, such as D-lysergic acid diethylamide (LSD; Aghajanian et al., 1968), $N, N$-dimethyltryptamine (DMT; Aghajanian et al., 1970), or 5methoxy- $N, N$-dimethyltryptamine (5-MeODMT; Mosko and Jacobs, 1977; deMontigny and Aghajanian, 1977). Moreover, local (microiontophoretic) application of these compounds as well as various structurally related indoleamines, including 5-HT, produce direct depressant effects on neuronal firing (Aghajanian et al., 1972; Haigler and Aghajanian, 1974; Aghajanian and Haigler, 1975;

\footnotetext{
' We thank Nancy Margiotta and Annette Zimnewicz for their skilled technical assistance. Dr. A. A. Manian generously provided many of the drugs used in this study. 'This work was supported by United States Public Health Service Grants MH-17871, MH-14459, and GM-7324 and by the State of Connecticut.

${ }^{2}$ To whom correspondence should be addressed at his present address: Laboratory of Neurophysiology, National Institute of Neurological and Communicative Disorders and Stroke, National Institutes of Health, Bethesda, MD 20205.
}

Bramwell and Göyne, 1976; deMontigny and Aghajanian, 1977). These observations have led to the concept that raphe 5-HT neurons possess inhibitory somatodendritic 5 -H'T receptors. Because these receptors are sensitive to the 5-HT neuron's own neurotransmitter, they have been termed "autoreceptors." The ultimate functional significance of $5-\mathrm{HT}$ autoreceptors may be as a link in the autoregulatory control of 5-HT neuron firing (see Aghajanian and Wang, 1978).

By analogy with the subclassification of $\alpha$-noradrenergic receptors where norepinephrine neuron autoreceptors are of the $\alpha_{2}$ subtype (Langer, 1974; Berthelsen and Pettinger, 1977; Cedarbaum and Aghajanian, 1977), 5$\mathrm{HT}$ autoreceptors may be denoted " $\mathrm{S}_{2}$ serotonergic receptors" (Aghajanian, 1981). $\mathrm{S}_{2}$ receptors exhibit significant pharmacological differences from "postsynaptic" 5HT receptors (i.e., 5 -HT receptors on neurons which are innervated by central serotonergic neurons). To date, two types of postsynaptic 5-HT receptors have been described, those mediating facilitation and those mediating suppression of neuronal firing, which have been denoted " $\mathrm{S}_{1}$ " and " $\mathrm{S}_{3}$," respectively (Aghajanian, 1981). Although 5-HT is about equally active at all receptor subtypes, $\mathrm{S}_{2}$ autoreceptors respond preferentially to hallucinogenic indoleamines and related compounds. Thus, 
LSD, 5-methoxytryptamine (5-MeOT), and 5-MeODMT are considerably more potent than $5-\mathrm{HT}$ as agonists at $\mathrm{S}_{2}$ receptors, whereas these compounds are relatively weak when compared to 5 -HT at $\mathrm{S}_{3}$ receptors (Aghajanian and Haigler, 1975; deMontigny and Aghajanian, 1977).

Although it is clear that certain modifications of the 5HT molecule can alter its activity at $S_{2}$ receptors markedly, there is limited information concerning the exact structural requirements of the receptor. In the present study, the pharmacological characteristics of $S_{2}$ receptors are examined in detail using a series of closely related 5HT analogs. These compounds were designed to test the significance of various ring substituents and the presence or absence of $N, N$-dimethylation on the expression of physiological activity at $S_{2}$ receptors. The results indicate certain rather strict rules for agonist activity of indoleethylamines at dorsal raphe $S_{2}$ receptors.

\section{Materials and Methods}

Fifty-four male Sprague-Dawley rats (Charles River Laboratories, Inc., Wilmington, MA) weighing 190 to 290 gm were used in these experiments. The animals were anesthetized with chloral hydrate $(350 \mathrm{mg} / \mathrm{kg}$, i.p.) and mounted in a stereotaxic apparatus; additional anesthetic injections were given as necessary during the course of the experiment. Prior studies have failed to detect any significant effect of chloral hydrate on the spontaneous activity or responsiveness of raphe neurons (Aghajanian et al., 1972; Haigler and Aghajanian, 1974; Mosko and Jacobs, 1977). Body temperature was maintained between 36 and $37^{\circ} \mathrm{C}$ with a heating pad. In some animals, a lateral tail vein was cannulated with a 25 gauge hypodermic needle for intravenous administration of drug solutions. In these intravenous drug experiments, extracellular unitary action potentials of raphe neurons were monitored with single barrel glass micropipettes. The electrodes were broken back to a tip diameter of 1 to 2 $\mu \mathrm{m}$ and were filled with $2 \mathrm{M} \mathrm{NaCl}, 2 \%$ Pontamine sky blue solution. The in vitro impedances of these electrodes were typically 3 to 6 megohms.

For application of drugs by microiontophoresis, conventional five-barrel micropipettes were prepared as described by Haigler and Aghajanian (1974). The center barrel (used for recording) was filled with the $\mathrm{NaCl} / \mathrm{dye}$ solution. Three of the side barrels were loaded with drug solutions and the remaining barrel contained $4 \mathrm{M} \mathrm{NaCl}$ for automatic current balancing. Electrodes with recording barrel impedances of 3.5 to 5 megohms were usually suitable for simultaneous recording and drug ejection. A retaining current of $-10 \mathrm{nA}$ was applied to the drug barrels between ejection periods.

In preparation for recording, a burr hole was drilled in the calvaria overlying the dorsal raphe nucleus. The dura was retracted and the perimeter of the hole was packed with a small amount of bone wax to prevent oozing of blood from the sagittal sinus. The microelectrode was lowered into the dorsal raphe which is located on the midline, approximately 0.3 to $0.5 \mathrm{~mm}$ anterior to the lambdoidal suture. Units exhibiting characteristics of serotonergic neurons as determined by histochemical and electrophysiological criteria (see Aghajanian and Wang, 1978) usually were encountered 5.5 to $6.6 \mathrm{~mm}$ ventral to the skull surface. These units had a slow, regular spontaneous firing rate (typically 0.2 to 2 spikes/sec) and wide, positive-negative extracellular action potentials (1 to 2 msec in duration).

In experiments where drug solutions were administered systemically, only one cell per animal was tested. After obtaining an indication of the cell's base line firing rate, boluses of the test drug were infused intravenously. Additional injections were administered until the cell transiently ceased firing. Following partial or complete recovery, LSD often was injected to confirm that the cell exhibited the characteristic depression of serotonergic neurons seen with this drug (Aghajanian et al., 1968). Only the presumably more lipophilic $N, N$-dimethylated derivatives were tested by the systemic route. Since 5MeOT does not enter the brain to any appreciable extent when administered parenterally (in the absence of a monoamine oxidase inhibitor), whereas 5-MeODMT does (Green et al., 1975; Sanders and Bush, 1967; deMontigny and Aghajanian, 1977), the assumption was made that the other primary amines similarly would have limited access to the brain and therefore were not administered intravenously. A wider range of compounds could be tested, however, using iontophoresis.

In iontophoretic experiments, a series of cells in each animal was studied. An attempt was made to test all three drugs carried in the pipette on each cell, but this was not always possible because some cells were lost before completion of the sequence. The potency of drugs was estimated using the $I T_{50}$ method of deMontigny and Aghajanian (1977). In a typical experiment, the base line firing rate of a cell was established and 60-sec pulses of the test drug were applied with intervals of at least 60 sec between ejections. An iontophoretic current was established which produced a rapid suppression of firing (usually $50 \%$ in 20 to 40 sec). For each ejection which produced greater than $50 \%$ depression, the $I T_{50}$ was calculated where $I$ is the current in nanoamperes and $T_{50}$ is the time in seconds required to obtain $50 \%$ suppression of firing. The $I T_{50}$ is the total charge ejected at $T_{50}$ and is proportional to the dose of the drug producing a $50 \%$ suppression of firing; thus, the more potent the drug, the lower the $I T_{50}$. Drug potencies can be compared using $I T_{50}$ values if they can be assumed to have similar transport numbers. Because of uncertainties in the transport numbers and the unknown relationship between the dose applied and the resultant concentration of the drug in the vicinity of the cell, the $I T_{50}$ values are used only to rank drugs and cannot be taken as quantitative estimates of drug potencies. In practice, the $I T_{50}$ method provides a means to assess the potency of compounds requiring widely differing iontophoretic currents to achieve similar degrees of inhibition of raphe firing.

$I T_{50}$ values obtained on the same cell were averaged and the geometric mean (antilog of the mean log) of values among cells was determined along with the $95 \%$ confidence interval (see Wang et al., 1979).

At the end of each experiment, the final electrode position was verified by iontophoretically ejecting dye from the recording electrode ( $20 \mu \mathrm{A}$ for 20 to $60 \mathrm{~min})$ and locating the spot thus produced in brain sections prepared by routine histological methods.

Solutions for intravenous administration were pre- 
pared by dissolving the drug powder in a small amount of aqueous tartaric acid. The $\mathrm{pH}$ was adjusted to 4.0 with $\mathrm{NaOH}, \mathrm{NaCl}$ was added to make a final concentration of $0.9 \%$, and the solution was brought to the appropriate volume with deionized water. Iontophoretic solutions were all $0.1 \mathrm{~m}, \mathrm{pH} 4$, except 5 -HT which was $0.04 \mathrm{M}$. The drugs tested in this study are listed in Table I along with their structures. All were prepared by Regis Chemical Co. and many were obtained through the courtesy of Dr. A. A. Manian, National Institute of Mental Health. LSD was provided by the Food and Drug AdministrationPublic Health Service Psychotomimetics Advisory Committee.

\section{Results}

Systemically administered DMT derivatives. When administered intravenously, each of a series of methoxysubstituted DMT derivatives produced a rapid, transient suppression of the spontaneous firing of raphe neurons (Fig. 1; Table II). In confirmation of previous observations (deMontigny and Aghajanian, 1977; Mosko and Jacobs, 1977; Trulson and Jacobs, 1979), 5-McODMT was exceptionally potent in this regard. 'This drug produced a complete cessation of firing at doses of 20 to 40 $\mu \mathrm{g} / \mathrm{kg}$.

DMT derivatives with methoxy substitutions at the 4or 6-positions on the indole nucleus were far less active than 5-MeODMT. The potencies of these compounds were comparable to that of DMT itself (see Aghajanian et al., 1970) which, on a molar basis, is 20 to 40 times weaker than 5-MeODMT. As noted in Table II, 4-MeODMT was slightly more potent than DMT, whereas 6MeODMT was the least active of the mono-ring-substituted DMT derivatives. Addition of a methoxy group at the 7-position of 5-MeODMT to form 5,7-diMeODMT resulted in a striking fall in potency (Fig. 1; Table II).
Iontophoretic studies. A series of nine tryptamine derivatives were examined in iontophoretic studies. The compounds tested consisted of 5-HT, 5-MeOT, and 5MeODMT and their analogs having ring substitutions at either the 4- or 6-positions instead of at the 5-position (Table I). Although their potencies varied markedly, all of these compounds produced a suppression of the firing of raphe neurons when applied iontophoretically with currents of 10 to $35 \mathrm{nA}$ (Fig. 2). The $I T_{50}$ values for each

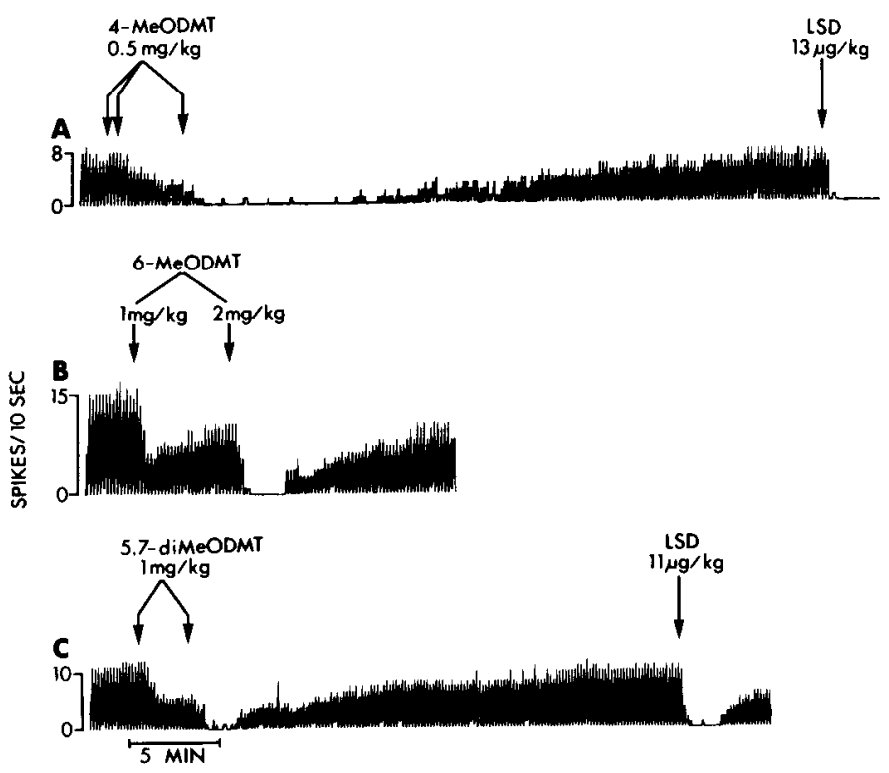

Figure 1. Integrated rate records demonstrating the suppression of dorsal raphe unit activity by intravenously administered 4-MeODMT $(A)$, 6-MeODMT $(B)$, and 5,7-diMeODMT $(C)$. Following recovery in $A$ and $C$, D-lysergic acid diethylamide (LSD) produces its characteristic depressant effect. See Table I for the key to the abbreviations.

TABLE I

Structures of compounds tested

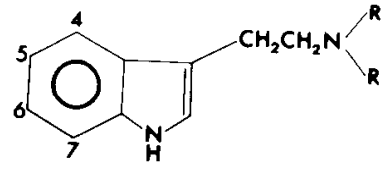

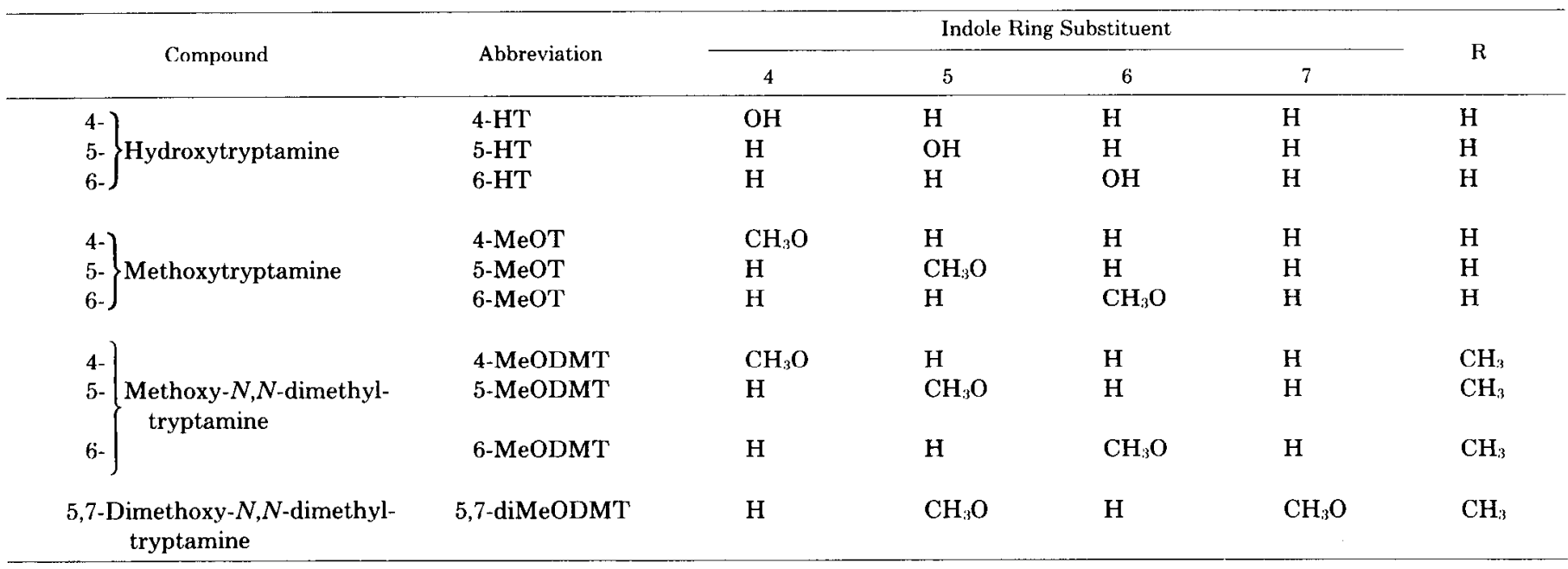


TABLE II

Comparison of the efficacies of intravenously administered DMT derivatives in suppressing raphe neuron spontaneous activity

\begin{tabular}{lcc}
\hline \multicolumn{1}{c}{ Drug } & Number of Animals & Dose Range $^{a}$ \\
& & $\mathrm{mg} / \mathrm{kg}$ \\
4-MeODMT & 10 & $0.25-1.5$ \\
5-MeODMT & 2 & $0.02-0.04$ \\
6-MeODMT & 5 & $1-3$ \\
5,7-diMeODMT & 4 & $1-3$ \\
DMT $^{b}$ & & $0.04-1.5$ \\
\hline
\end{tabular}

"Cumulative intravenous dose required to produce complete cessation of firing. Cells generally resumed firing within $2 \mathrm{~min}$, but the time to full recovery was variable.

"Data from Aghajanian et al. (1970).

compound are summarized in Figure 3 . The potency differences among the structural analogs is illustrated in Figure 2. In Figure 2, $A$ and $C$, similar iontophoretic currents produce markedly different responses on the same raphe neuron. In Figure $2 B$, comparable depressant effects are obtained with iontophoretic currents of different intensities. Note that, even at high iontophoretic currents, 6 -MeOT does not produce a complete suppression of firing.

\section{Discussion}

The present results demonstrate that minor modifications in the 5-HT molecule can produce large changes in potency at $S_{2}$ receptors on raphe serotonergic neurons. Certain structure-activity rules are readily apparent from the data summarized in Table II and Figure 3. First, compounds with either hydroxy or methoxy substituents at the 5-position are more active than their analogs with these groups at the 4-or 6-positions. Second, activity is retained to a greater degree when the ring substituent is shifted from the 5- to the 4-position than from the 5- to the 6-position. Third, moving a methoxy group from the 5 - to the 4- or 6-position produces a larger drop in activity than does shifting a hydroxy group. Fourth, $N, N$-dimethylation results in an increase in activity of the methoxy-substituted derivatives.

Of primary importance in determining activity is the presence or absence of a substituent at the 5-position on the tryptamine nucleus. This may indicate that the 5position functional group interacts in a critical fashion with the $\mathrm{S}_{2}$ receptor. However, as Weinstein et al. (1978) have noted, substitution at this site produces marked alterations in the electronic character of the entire molecule. Therefore, activity may be affected by changes in the physical or chemical properties of the molecule as well as (or instead of) a direct interaction with the receptor at this locus.

Although hydroxy or methoxy substitution at a site on the benzene ring other than the 5-carbon atom results in reduced activity, the 4-position is more favorable than the 6-position. The enhanced activity of 4-HT compared to 6 - $\mathrm{HT}$ may reflect the ability of the side chain amino function to hydrogen bond with the 4-hydroxyl on the indole ring. As suggested by Snyder and Richelson (1968), this would stabilize a conformation in which the side chain was folded back into a third ring. Such a structure would more closely resemble LSD, a potent agonist of
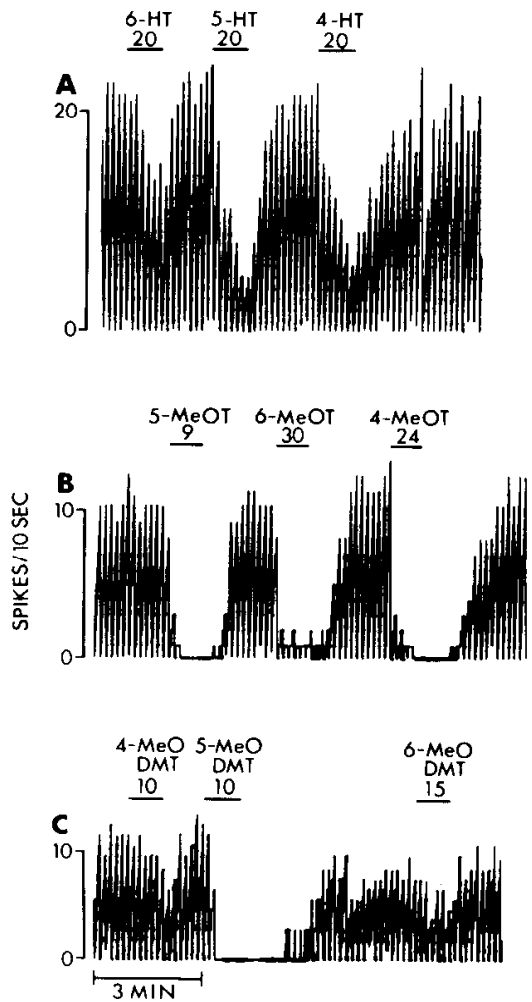

Figure 2. Comparison of the response of dorsal raphe units to iontophoretically administered tryptamine derivatives. $A$, With equal iontophoretic currents, 5 -HT produces the greatest depressant effect, whereas 4 -HT and $6-\mathrm{H}^{\prime} \mathrm{T}$ have weaker activity. Note the prolonged nature of the response to 4-HT. $B$, Complete suppression of activity by low currents of 5-MeOT; much higher currents of $6-\mathrm{MeOT}$ and 4-MeOT are required to produce comparable effects. $C$, Powerful depressant effect of 5 MeODMT is contrasted with the weak responses to 4-MeODMT and 6-MeODMT. Each record represents a separate unit in a different animal. The bars above records indicate the duration of the iontophoretic ejection. The numbers refer to the iontophoretic current in nanoamperes. See Table I for the key to the abbreviations.

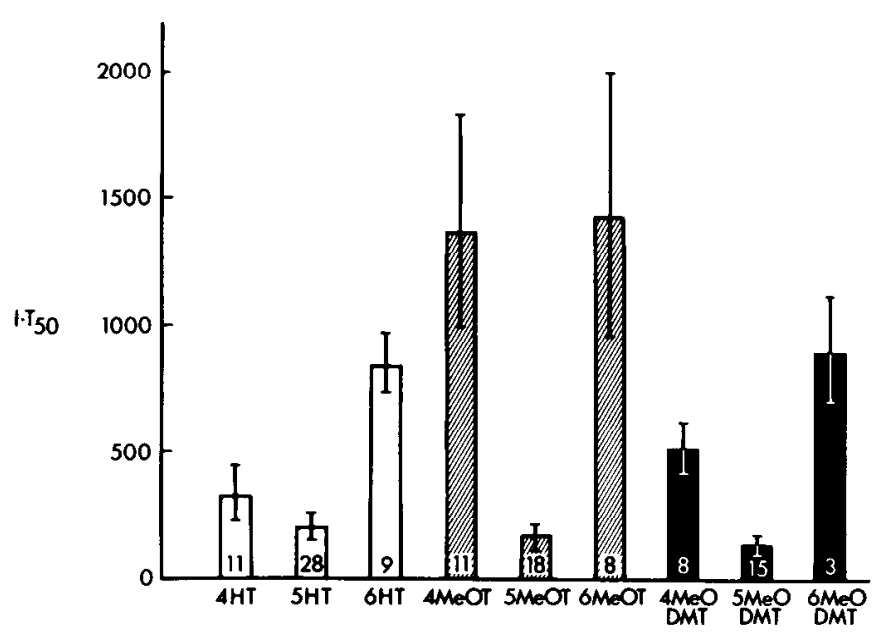

Figure 3. Comparison of the efficacies of iontophoretically applied tryptamine derivatives in suppressing dorsal raphe unit activity. Data are expressed as the geometric mean of $I T_{50}$ values among cells. The lines represent $95 \%$ confidence intervals. The number of cells tested is indicated by the numerals within the bars. See Table I for the key to the abbreviations. 
the $S_{2}$ receptor. The weaker activity of 4-MeO'T compared to 4-HT may be due to the fact that the methoxy group is not able to interact as strongly with the amino nitrogen to form a stable structure.

In general, increasing the hydrophobic nature of the tryptamine molecule by $O$-methylation or $N, N$-dimethylation produces an enhancement of activity except when this occurs at an unfavorable ring position, in which case, there is a strong reduction in activity. Thus, it is apparent that alterations in hydrophobicity do not account completely for the potency differences among drugs. 'The specific nature of the drug-receptor interaction is indicated further by examination of the partition coefficients for the DMT derivatives as determined by Glennon and Gessner (1979). The rank ordering of these values, which represent the hydrophobic character of the molecule, are 6-MeODMT > 5-MeODMT > 4-MeODMT. This ordering does not correspond to the activity that these drugs display in depressing raphe neurons when they are applied iontophoretically or administered intravenously (Table II; Fig. 3).

It is particularly significant that the intravenous potencies do not depend upon hydrophobicity since this suggests that variations in penetration into the brain (which are presumably related to the lipophilic character of the molecule) do not account for the potency differences. Moreover, the relative potency series for the DMT derivatives is the same whether the drugs are administered systemically or by iontophoresis. In both cases, the rank ordering is 5-MeODMT $>4-\mathrm{MeODMT}>6-\mathrm{Me}-$ ODMT. This indicates that the differences in potency seen in the iontophoretic studies represent biologically meaningful differences in pharmacological activity rather than variations in transport from the iontophoretic pipettes. Conversely, it seems unlikely that the effects of the intravenous compounds are due to systemic or indirect actions. The rank ordering displayed by the DMT derivatives at the $S_{2}$ receptor also corresponds to the activity that these compounds exhibit in a behavioral model where 5-MeODMT is used as a discriminative stimulus (Glennon et al., 1980).

The structure-activity rules developed in the present study are similar in some respects to those determined in the isolated rat fundus preparation, the most extensively studied peripheral model of 5 -HT receptor function (Vane, 1959; Glennon and Gessner, 1979). In the rat stomach, hydroxy or methoxy substitution at the 5-position markedly enhances binding to the 5-HT receptor. Addition of these groups to the 4-position produces intermediate affinity, whereas substitution at the 6-position and in particular at the 7-position strongly decrease binding (Glennon and Gessner, 1979). On the basis of the observation that a polar substituent at the 7-position produces a marked decrease in activity in spite of the fact that the electronic properties of the molecule would theoretically predict high binding affinity, Johnson and Green (1974) suggested that the 7-position on the indole nucleus might come in contact with a hydrophobic region of the receptor and sterically hinder binding. This would explain the marked reduction in activity of $5,7-\mathrm{diMe}$ ODMT compared to 5-MeODMT.

One structure-activity rule observed in the rat fundus system which does not appear to hold for the brain $S_{2}$ receptor is that $5-\mathrm{MeOT}$ has weaker biological activity than 5-HT (Vane, 1959; Green et al., 1978). Rather, 5MeOT and 5-MeODMT as well are more potent than 5$\mathrm{HT}$ at the $\mathrm{S}_{2}$ receptor (deMontigny and Aghajanian, 1977). Thus, one distinguishing characteristic of the $S_{2}$ receptor is that the 5-methoxy compounds have greater activity than the presumed natural agonist $5-\mathrm{HT}$. This observation cannot be attributed to differences in transport from the iontophoretic pipettes as the same compounds are less potent than $5-\mathrm{H} T$ at central $\mathrm{S}_{3}$ receptors (see deMontigny and Aghajanian, 1977).

An additional distinction between the rat fundus 5-HT receptor and the brain $S_{2}$ receptor is that, in the peripheral system, $N, N$-dimethylation reduces affinity (Glennon and Gessner, 1979). However, as a different series of drugs were used to arrive at this conclusion, the confirmation of a true difference regarding this structureactivity rule must await further studies.

In contrast to the extensive data concerning the interaction of substituted tryptamines with peripheral 5-HT receptors, little information is available with respect to the binding of these compounds in the central nervous system. Recently it has been reported that two distinct 5-HT receptor populations can be distinguished in brain using the radioligands $\left[{ }^{3} \mathrm{H}\right] 5-\mathrm{HT}$ and $\left[{ }^{3} \mathrm{H}\right]$ spiroperidol (Peroutka and Snyder, 1979). The limited data presently available would suggest that neither of these sites corresponds to the $S_{2}$ receptor as characterized in the present study. Thus, 5-MeOT and 5-MeODMT have a lower affinity than 5 -HT for brain $\left[{ }^{3} \mathrm{H}\right] 5-\mathrm{HT}$ receptors (Fillion et al., 1978; Whitaker and Seeman, 1978; Peroutka and Snyder, 1979; Segawa et al., 1979; Middlemiss et al., 1980 ), whereas they are more potent than 5 -HT in suppressing raphe neuron firing. The pharmacological nonidentity of the $\mathrm{S}_{2}$ receptor and the $\left[{ }^{3} \mathrm{H}\right] 5-\mathrm{HT}$ binding site is consistent with their suspected respective pre- and postsynaptic localizations (Fillion et al., 1978; Nelson et al., 1978). Locally applied $S_{2}$ agonists have direct effects on raphe 5-HT neurons, suggesting that the $S_{2}$ receptor is present on these neurons. On the other hand, as the binding of $\left[{ }^{3} \mathrm{H}\right] 5$ - $\mathrm{HT}$ is not reduced by the destruction of 5-HT neurons, it has been proposed that the binding sites are predominantly postsynaptic (Seeman et al., 1980; Bennett and Snyder, 1976; Fillion et al., 1978; Nelson et al., 1978; Segawa et al., 1979).

$\left[{ }^{3} \mathrm{H}\right]$ Spiroperidol, like $\left[{ }^{3} \mathrm{H}\right] 5-\mathrm{HT}$, does not appear to label $S_{2}$ receptors as 5-MeOT and 5-MeODMT are approximately equipotent with 5-HT in displacing the ligand from brain membranes (Peroutka and Snyder, 1979; Middlemiss, 1980). Moreover, 2-bromo-LSD, an analog of LSD with reduced activity at $S_{2}$ receptors (Aghajanian et al., 1970; Aghajanian, 1976), has greater affinity than LSD for $\left[{ }^{3} \mathrm{H}\right]$ spiroperidol binding sites (Peroutka and Snyder, 1979). [ $\left.{ }^{3} \mathrm{H}\right]$ Spiroperidol also seems to bind to postsynaptic sites (Seeman et al., 1980).

The binding of $\left[{ }^{3} \mathrm{H}\right] \mathrm{LSD}$, which is claimed to label both the 5-HT and spiroperidol sites (Peroutka and Snyder, 1979), nevertheless may be the best biochemical model for the $S_{2}$ receptor. Thus, 5-MeODMT has a considerably higher affinity for the $\left[{ }^{3} \mathrm{H}\right] \mathrm{LSD}$ receptor than does 5-HT (Lovell and Freedman, 1976), although 5-MeOT has been reported to have a greater (Bennett and Snyder, 1975), equal (Bennett and Snyder, 1976; 
Green et al., 1978), or weaker (Fillion et al., 1978; Peroutka and Snyder, 1979) affinity. Moreover, the ringhydroxylated tryptamines show the rank order of potencies 5 -HT > 4-HT > 6-HT (Green et al., 1978) which is identical to that observed for the $S_{2}$ receptor. LSD (deMontigny and Aghajanian, 1977) and lisuride (Rogawski and Aghajanian, 1979), the two most powerful known agonists at $S_{2}$ receptors, are similarly the most potent displacers of $\left[{ }^{3} \mathrm{H}\right] \mathrm{LSD}$ binding (Bennett and Aghajanian, 1974; Lovell and Freedman, 1976; Bennett and Snyder, 1975, 1976; Green et al., 1978; Fillion et al., 1978; Peroutka and Snyder, 1979; Fuxe et al., 1978). In most cases, 2-bromo-LSD has been reported to have lower affinity than LSD for $\left[{ }^{3} \mathrm{H}\right] \mathrm{LSD}$ binding sites although the magnitude of this difference varies among studies and is usually small (Bennett and Snyder, 1976; Lovell and Freedman, 1976; Peroutka and Snyder, 1979). Of the ligands believed to label central nervous system 5 HT receptors, LSD binds to a site with pharmacological characteristics most closely resembling the $S_{2}$ receptor, although the data upon which to base this conclusion is limited. The significance of this observation, especially with regard to the supposed mixed nature of $\left[{ }^{3} \mathrm{H}\right] \mathrm{LSD}$ binding, is unclear. Nevertheless, it is of interest to note that $\left[{ }^{3} \mathrm{H}\right]$ LSD binding is saturated at approximately the concentration obtained in situ following a dose of LSD which just suppresses raphe serotonergic neurons (Bennett and Aghajanian, 1974). This further demonstrates the pharmacological correspondence between $\left[{ }^{3} \mathrm{H}\right] \mathrm{LSD}$ binding and the $S_{2}$ receptor. However, since most of the $\left[{ }^{3} \mathrm{H}\right] \mathrm{LSD}$ binding which is detectable in brain homogenates occurs postsynaptically (Bennett and Aghajanian, 1974; Bennett and Snyder, 1975, 1976; Fillion et al., 1978), whereas the $\mathrm{S}_{2}$ site as defined physiologically is presumably presynaptic, the two receptors cannot be considered identical.

\section{References}

Aghajanian, G. K. (1976) LSD and 2-bromo-LSD: Comparison of effects on serotonergic neurones and on neurones in two serotonergic projection areas, the ventral lateral geniculate and amygdala. Neuropharmacology 15: 521-528.

Aghajanian, G. K. (1981) The modulatory role of serotonin at multiple receptors in brain. In Serotonin Neurotransmission and Behavior, B. L. Jacobs and A. Gelperin, eds., pp. 156185, MIT Press, Cambridge, MA.

Aghajanian, G. K., and H. J. Haigler (1975) Hallucinogenic indoleamines: Preferential action upon presynaptic serotonin receptors. Psychopharmacol. Commun. 1: 619-629.

Aghajanian, G. K., and R. Y. Wang (1978) Physiology and pharmacology of central serotonergic neurons. In Psychopharmacology: A Generation of Progress, M. A. Lipton, A. DiMasco, and K. F. Killam, eds., Raven Press, New York.

Aghajanian, G. K., W. E. Foote, and M. H. Sheard (1968) Lysergic acid diethylamide: Sensitive neuronal units in the midbrain raphe. Science 161: 706-708.

Aghajanian, G. K., W. E. Foote, and M. H. Sheard (1970) Actions of psychotogenic drugs on single midbrain raphe neurons. J. Pharmacol. Exp. Ther. 171: 178-187.

Aghajanian, G. K., H. J. Haigler, and F. E. Bloom (1972) Lysergic acid diethylamide and serotonin: Direct actions on serotonin-containing neurons. Life Sci. 11: 615-622.

Bennett, J. L., and G. K. Aghajanian (1974) D-LSD binding to brain homogenates: Possible relationship to serotonin receptors. Life Sci. 15: 1935-1944.
Bennett; J. P., Jr., and S. H. Snyder (1975) Stereospecific binding of D-lysergic acid diethylamide (LSD) to brain membranes: Relationship to serotonin receptors. Brain Res. 94: 523-544.

Bennett, J. P., Jr., and S. H. Snyder (1976) Serotonin and lysergic acid diethylamide binding in rat brain membranes: Relationship to postsynaptic serotonin receptors. Mol. Pharmacol. 12: 373-389.

Berthelsen, S., and W. A. Pettinger (1977) A functional basis for classification of $\alpha$-adrenergic receptors. Life Sci. 21: 595606.

Bramwell, G. J., and T. Göyne (1976) Responses of midbrain neurons to microiontophoretically applied 5-hydroxytryptamine: Comparison with the response to intravenously administered lysergic acid diethylamide. Neuropharmacology 15: 456-461.

Cedarbaum, J. M., and G. K. Aghajanian (1977) Catecholamine receptors on locus coeruleus neurons: Pharmacological characterization. Eur. J. Pharmacol. 44: 375-385.

deMontigny, C., and G. K. Aghajanian (1977) Preferential action on 5-methoxytryptamine and 5-methoxydimethyltryptamine on presynaptic serotonin receptors: A comparative iontophoretic study with LSD and serotonin. Neuropharmacology 16: 811-818.

Fillion, G. M. B., J. -C. Rousselle, M. -P. Fillion, D. M. Beaudoin, M. R. Goiny, J. -P. Deniau, and J. J. Jacobs (1978) High-affinity binding of $\left[{ }^{3} \mathrm{H}\right] 5$-hydroxytryptamine to brain synaptosomal membranes: Comparison with [ $\left.{ }^{3} \mathrm{H}\right]$ lysergic acid diethylamide binding. Mol. Pharmacol. 14: 50-59.

Fuxe, K., B. B. Fredholm, S. -O. Ögren, L. F. Agnati, T. Hökfelt, and J. - $\AA$. Custafsson (1978) Ergot drugs and central monoaminergic mechanisms: A histochemical, biochemical and behavioral analysis. Fed. Proc. 37: 2181-2191.

Glennon, R. A., and P. K. Gessner (1979) Serotonin receptor binding affinities of tryptamine analogues. J. Med. Chem. 22: 428-432.

Glennon, R. A., R. Young, J. A. Rosecrans, and M. J. Kallman (1980) Hallucinogenic agents as discriminative stimuli: A correlation with serotonin receptor affinities. Psychopharmacology (Berlin) 68: 155-158.

Green, A. R., J. P. Hughes, and A. F. C. Tordoff (1975) The concentration of 5-methoxytryptamine in rat brain and its effects on behavior following its peripheral injection. Neuropharmacology 14: 601-606.

Green, J. P., C. L. Johnson, H. Weinstein, S. Kang, and D. Chou (1978) Molecular determinants for interaction with the LSD receptor: Biological studies and quantum chemical analysis. In The Psychopharmacology of Hallucinogens, R. C. Stillman and R. E. Willette, eds., pp. 28-60, Pergamon Press, New York.

Haigler, H. J., and G. K. Aghajanian (1974) Lysergic acid diethylamide and serotonin: A comparison of effects on serotonergic neurons and neurons receiving a serotonergic input. J. Pharmacol. Exp. Ther. 188: 688-699.

Johnson, C. L., and J. P. Green (1974) Molecular orbital studies of tryptamines active on the LSD receptor of the rat fundus strip. Int. J. Quantum. Chem. Symp. 1: 159-167.

Langer, S. Z. (1974) Presynaptic regulation of catecholamine release. Biochem. Pharmacol. 23: 1793-1800.

Lovell, R. A., and D. X. Freedman (1976) Stereospecific receptor sites for $d$-lysergic acid diethylamide in rat brain: Effects of neurotransmitters, amine antagonists, and other psychotropic drugs. Mol. Pharmacol. 12: 620-630.

Middlemiss, D. N., J. A. Carroll, R. W. Fisher, and I. .J. Mounsey (1980) Does $\left[{ }^{3} \mathrm{H}\right]$ spiroperidol label a $5-\mathrm{HT}$ receptor in the frontal cortex of the rat? Eur. J. Pharmacol. 66: 253-254.

Mosko, S. S., and B. L. Jacobs (1977) Electrophysiological evidence against negative neuronal feedback from the forebrain controlling midbrain unit activity. Brain Res. 119: 291303. 
Nelson, D. L., A. Herbet, S. Bourgoin, J. Glowinski, and M. Hamon (1978) Characteristics of central 5-HT receptors and their adaptive changes following intracerebral 5,7-dihydroxytryptamine administration in the rat. Mol. Pharmacol. 14: 983-995.

Peroutka, S. J., and S. H. Snyder (1979) Multiple serotonin receptors: Differential binding of $\left[{ }^{3} \mathrm{H}\right] 5$-hydroxytryptamine, $\left[{ }^{3} \mathrm{H}\right]$ lysergic acid diethylamide and $\left[{ }^{3} \mathrm{H}\right]$ spiroperidol. Mol. Pharmacol. 16: 687-699.

Rogawski, M. A., and G. K. Aghajanian (1979) Response of central monoaminergic neurons to lisuiride: Comparison with LSD. Life Sci. 24: 1289-1298.

Sanders, E., and M. T. Bush (1967) Distribution, metabolism and excretion of bufotenine in the rat with prelininary studies of its $O$-methyl derivative. J. Pharmacol. Exp. Ther. 158: 340-352.

Seeman, P., K. Westman, D. Coscina, and J. J. Warsh (1980) Serotonin receptors in hippocampus and frontal cortex. Eur. J. Pharmacol. 66: 179-191.

Segawa, T., T. Mizuta, and Y. Nomura (1979) Modification of central 5-hydroxytryptamine binding sites in synaptic membranes from rat brain after long-term administration of tri- cyclic antidepressants. Eur. J. Pharmacol. 58: 75-83.

Snyder, S. H., and E. Richelson (1968) Psychedelic drug: Steric factors that predict psychotropic activity. Proc. Natl. Acad. Sci. U. S. A. 60: 206-213.

Trulson, M. E., and B. L. Jacobs (1979) Effect of 5-methoxy- $N$ $N$-dimethyltryptamine on behavior and raphe unit activity in freely moving cats. Eur. J. Pharmacol. 54: 43-50.

Vane, J. R. (1959) The relative activities of some tryptamine analogues on the isolated rat stomach strip preparation. $\mathrm{Br}$. J. Pharmacol. 14: 87-98.

Wang, R. Y., C. deMontigny, B. I. Gold, R. H. Roth, and G. K. Aghajanian (1979) Denervation supersensitivity to serotonin in rat forebrain: Single cell studies. Brain Res. 178: 479-497.

Weinstein, H., J. P. Green, R. Osman, and W. D. Edwards (1978) Recognition and activation mechanisms on the LSD/ serotonin receptor: The molecular basis of structure-activity relationships. In 'QuaSAR' Research Monograph 22, G. Barnett, M. Trsic, and R. Willetto, eds., pp. 333-358, National Institute on Drug Abuse, Bethesda, MD.

Whitaker, P. M., and P. Seeman (1978) High-affinity ${ }^{3} \mathrm{H}$-serotonin binding to caudate: Inhibition by hallucinogens and serotonergic drugs. Psychopharmacology (Berlin) 59: 1-5. 